\title{
QUALITY OF WORK LIFE (QWL) AND ABSENTEEISM INDEX (AI) IN A SMALL BUSINESS
}

\author{
N.M. STEFANO ${ }^{\dagger}$, L.G.L. VERGARA ${ }^{\dagger}$, L.P. GODOY ${ }^{\ddagger}$ and M.C.D. FREITAS ${ }^{\S}$ \\ $\uparrow$ Postgraduate Program in Production Engineering, Federal University of Santa Catarina, Florianopolis, \\ Santa Catarina,Brazil.E-mail: stefano.nara@gmail.com,lizandravergara@gmail.com \\ $\$$ Postgraduate Program in Production Engineering, Federal University of Santa Maria, Santa Maria, \\ Rio Grande do Sul, Brazil.E-mail: leoni_godoy@yahoo.com.br \\ $\S$ Postgraduate Program in Production Engineering, Federal University of Paraná, Curitiba, Paraná, Brazil. \\ E-mail: carmemk2@gmail.com
}

\begin{abstract}
The competition between companies is generating a reduction in profitability ratios of the same, forcing the optimization of the production process, thus obtaining, greater efficiency in the allocation of factors of production involved. This research aims to correlate the rate of absenteeism with indicators of Quality of Work Life (QWL), through the results of a case study applied between employees of a brick small factory (pottery), located in central region of Rio Grande do Sul, Brazil. For this, a method of qualitative research was used, which enables the researcher to evaluate in detail the practice of improving QWL, as quantitative in the identification of satisfaction and absenteeism rates. It was found that in the company is no correlation between absenteeism and QWL, being the category of "attendants" that had the highest rate of absenteeism and job dissatisfaction, on issues of QWL. In general, it can be concluded that most of the causes of absenteeism is related to the low level of employees satisfaction with their work, undermining personal relationships, principles of QWL, and hence production levels.
\end{abstract}

Keywords - Human resources, Absenteeism, Job motivation.

\section{INTRODUCTION}

The area Human resources (HRs) of the organizations can establish a framework for the organizational diagnosis considering (Yeung and Bermam, 1997):

a) Determine what makes the success of the organization, i.e., what are the key organizational capabilities and which should be built to provide the satisfaction to stakeholders (customers, employees, shareholders or owners).

b) Understand how HR can add value to the critical factors of success, emphasizing the organizational capabilities that can generate satisfaction at all levels of stakeholders.

c) Design a proper measurement of the activities of HR, considering its operating activities, the performance of its corporate strategies.

The contribution of this diagnosis proposed by Yeung and Bermam (1997) lies in showing to the HR what are the points in which can add value and where there are gaps that need to be developed in terms of organizational capabilities; and these organizational capa- bilities are the link between strategy and action.

Satisfied employees seem more likely to speak well of the organization and help others to exceed expectations in relation to their work. That corroborates to statement what satisfied and committed employees to the organization have lower rates of absenteeism and turnover (Pfeifer, 2010). Organizational culture (Robbins, 2005; Rashid et al., 2004; Taormina, 2008; Naranjo-Valencia et al., 2011; Yeo and Li, 2011) has an impact on employee performance and satisfaction. Organizational culture is a system of values of values shared by the members, which helps differentiate an organization from the others, i.e., it refers to how employees perceive the characteristics of the culture of the organization.

The organizational culture acts as a variable interference (Robbins, 2005), because the employees form a perception generally subjective of the organization based on objective factors. This perception becomes effectively the organization's culture or personality, because, the objective factors are perceived and assimilated over the years by its employees. Therefore, the more intense is the culture, the greater its impact on performance and satisfaction of employees.

In this context, Human Resource Management (HRM) (Strohmeier and Piazza, 2013; Martin-Rios, 2014) has become a powerful differential, and therefore, a strategy adopted by companies to face the current scenario characterized by competitiveness. The HRM (Jabbour et al., 2011) involves planning, integration of all personnel and actions to reach it efficiently. The HRM (Osman et al., 2011) refers to systems, policies, and practices that influence the behavior (attitudes and performance) of employees. HRM practices include determining the needs of human resources, recruitment, selection, training, reward, evaluation, serving also to labor relations, health and safety issues and justice. The effective implementation of HRM practices in organizations is a major source of competitive advantage, and it has been demonstrated that it contributes positively to the organization's performance (Khandekar and Sharma, 2005; Collins, 2007; Ordonez de Pablos and Lytras, 2008). Some problems can be faced by HRM, such as: lack of motivation, increased employee turnover, workrelated illnesses, absenteeism, among many others; being absenteeism (Katz et al., 1985) responsible for large 